\title{
Diversitas Journal
}

ISSN 2525-5215

DOI: $10.17648 /$ diversitas-journal-v 1 i 1.379

Volume 1, Número 1 (jan./abr. 2016) pp: 48-54. www.kentron.ifal.edu.br/index.php/diversitas_journal (C) Diversitas Journal

\section{A história da educação em saúde e seus modelos de prática impostos à sociedade}

\author{
Ailson Darlan Sales Ferreira ${ }^{(1)}$; Ellyda Fernanda Lopes Costa ${ }^{(2)}$; \\ Karol Fireman de Farias $^{(3)}$; Rubens Pereira Bezerra ${ }^{(4)}$; Tiago Ferreira Dantas ${ }^{(5)}$; \\ Vinicius Silva Zacarias $^{(6)}$
}

(1)Estudante de Licenciatura em Química - Licenciatura Plena; Universidade Federal de Alagoas Campus Arapiraca; Arapiraca, Alagoas; ailsondarlan@hotmail.com; ${ }^{(2)}$ Estudante de Ciências Biológicas Licenciatura Plena; UFAL - Campus Arapiraca; ${ }^{(3)}$ Professora Assistente; UFAL - Campus Arapiraca; ${ }^{(4)}$ Estudante de Ciências Biológicas - Licenciatura Plena; UFAL - Campus Arapiraca; (5)Estudante de Enfermagem - Bacharelado; UFAL - Campus Arapiraca; ${ }^{(6)}$ Estudante de Arquitetura e Urbanismo Bacharelado; UFAL - Campus Arapiraca.

Todo o conteúdo expresso neste artigo é de inteira responsabilidade dos seus autores.

Recebido em: 20 de fevereiro de 2016; Aceito em: 20 de março de 2016; Publicado: 06 de novembro 2016. Copyright@ Autor, 2016.

RESUMO: A educação em saúde representa a formação de atitudes e valores que levam a sociedade ao comportamento inteligente, contribuindo para o benefício de sua saúde e da saúde dos outros, a exemplo da educação em saúde. As atividades de educação em saúde estão inseridas entre os compromissos dos profissionais de saúde, sendo perceptível que tais profissionais possuam um caráter informativo, repassando e explicando hábitos e comportamentos saudáveis, onde a disseminação dessas informações, geralmente são realizadas por meio de campanhas e publicadas pelos meios de comunicação em massa a toda à população. Esse estudo teve como objetivo compreender um pouco da história da educação em saúde e a sua importância para a sociedade. A pesquisa para a construção da revisão bibliográfica foi realizada através de livros e portal de dados. Os resultados mostraram que a eficácia da educação em saúde dependente apenas das tecnologias de ensino e aspectos relativos ao conteúdo sem haver o mínimo questionamento quanto aos resultados individuais e coletivos e, sem colocar em questão o vínculo dos problemas de saúde e condições de vida de grupos sociais específicos. Desta forma, os métodos atualmente adotados podem não ser muito viáveis para a população, uma vez que deixam a desejar quanto ao seu tempo de duração, alcance de classes sociais e afins.

Palavras-chave: Comportamento, População, Problemas.

ABSTRACT: Health education is the formation of attitudes and values that lead the company to
intelligent behavior, contributing to the benefit of your health and the health of others, such as health
education. Health education activities are inserted between the commitments of health professionals, with
noticeable that these professionals have an informative character, reviewing and explaining healthy habits
and behaviors, where the dissemination of such information, are generally carried out through campaigns
and published by from mass media to all the population. This study aimed to understand some of the
health education of history and its importance to society. The research for the construction of the
literature review was performed using books and data portal. The results showed that the effectiveness of
health education depend solely on the educational technologies and aspects of content without having the
least question about the individual and collective results, without putting into question the relationship of
health problems and living conditions of groups specific social. Thus, methods currently used can't be
very feasible for the population, once they leave to be desired as to their duration, range of social and
related classes.

Keywords: Behavior, Population, Problems. 


\section{INTRODUÇÃO}

A educação em saúde contribui para a disseminação do conhecimento acerca de algumas doenças ou de alguns cuidados que podem ser tomados para evitar algum tipo de acidente ou desenvolvimento de agravos. De acordo com Gavídia (1998) a educação em saúde pode ser compreendida como o princípio que busca orientar os indivíduos a agir de forma consciente perante a sua realidade cotidiana, ou seja, é um conjunto de atividades que sofrem influências e alterações de conhecimentos, atitudes e comportamentos, tendo em vista o aperfeiçoamento da qualidade de vida e de saúde do indivíduo.

A relação entre a educação e saúde, representa a formação de atitudes e valores que levam a sociedade ao comportamento inteligente, contribuindo para o benefício de sua saúde e da saúde dos outros, a exemplo da educação em saúde.

No Brasil, a ideia de uma metodologia abordando a saúde, surgiu pela primeira vez na segunda metade do século XIX, sendo aplicada tal prática apenas nas famílias da elite, customizando e urbanizando seus hábitos. Somente no início do século XX, as primeiras intervenções metodizadas de educação em saúde foram estendidas às classes populares, devido a necessidade de combater as epidemias, que estavam ocasionando transtornos a economia no país.

Nas últimas décadas, destaca-se um desenvolvimento surpreendente de reflexões teóricas e metodológicas abrangendo a educação em saúde com muitos programas e pesquisa nessa área. A elaboração de um sistema de saúde democrático que integre um processo social e político voltado para a saúde é de extrema importância. Atualmente, o governo do país disponibiliza aos brasileiros serviços de saúde, dos quais, e principalmente, o Sistema Único de Saúde (SUS), que tem como objetivo abranger ações assistenciais ou curativas e as atividades de promoção da saúde e prevenção de doenças.

As atividades de educação em saúde estão inseridas entre os compromissos dos profissionais de saúde, visando que os mesmos não se devem restringir à assistência curativa, e sim buscar dimensionar fatores de risco à saúde. Desta forma, é perceptível que tais profissionais possuam um caráter informativo, repassando e explicando hábitos e comportamentos saudáveis, induzindo os indivíduos a assumir novas práticas e condutas, prevenindo doenças e agravos.

A disseminação dessas informações, geralmente são realizadas por meio de campanhas e publicadas pelos meios de comunicação em massa a toda à população. As ações educativas visam a autonomia e a responsabilidade do cidadão com sua saúde 
conscientizando-o que as ações preventivas são mais lucrativas que as ações curativistas. Com isso, o objetivo deste estudo é compreender um pouco da história da educação em saúde e a sua importância para a sociedade.

\section{PROCEDIMENTO METODOLÓGICO}

Para a confecção da referida pesquisa realizou-se utilizado revisão bibliográfica em livros cujo conteúdo se adequava a temática abordada dos quais foi 1 obra encontrada, a partir desta foi realizada a leitura de alguns de seus capítulos, pois o resto não se tratava de fato com o que estava sendo procurado.

A pesquisa valeu-se também da revisão bibliográfica no portal de dados de periódicos da CAPES - Coordenação de Aperfeiçoamento de Pessoal de Nível Superior, a partir de uma busca feita com as palavras chave "health education" e "the importance of health education", onde foram encontrados mais de 1 milhão de resultados entre artigos, dissertações e teses, dentre esse grande numero de resultados aproveitou-se somente 2 pelo fato de condizer melhor com o objetivo da pesquisa.

Outra fonte bibliográfica para a pesquisa foi a plataforma do Google Acadêmico, onde foram encontrados mais de 60 milhões de resultados dos mais variados tipos, seja revistas, artigos, colunas de jornais, blogs, etc., porém apenas 7 de todos esses tiveram maior relevância acerca do tema envolvido; as palavras utilizadas como base da pesquisa foram “educação em saúde” e “a importância da educação em saúde na escola”.

\section{RESULTADOS E DISCUSSÃO}

Uma das maneiras mais disseminadas quando se fala sobre a educação e a saúde é aquela nas quais as execuções se intensificam mediante condições formais de ensinoaprendizagem, que funcionam junto ao locus das práticas de saúde. O didatismo é forma mais difundida nesses centros, pois ele parte do profissional de saúde em condição de “educador" em direção ao usuário dos serviços de saúde na condição de "educando”.

Segundo Vasconcelos, et al. (2009) o processo educativo gira em torno de uma pessoa que ensina a outra pessoa que não tem conhecimento acerca do assunto abordado. Ora aquele que está na posição de maior conhecimento do assunto põe-se em função de corrigir, vigiar e aconselhar aquele que está a aprender o ponto em questão, entretanto, 
há um grande risco de o profissional tomar-se como uma autoridade superior, ou seja, o único responsável pelo processo de aprendizagem. Mas, estamos deixando de lado alguns fatores externos que podem ser considerados como não preocupantes nesse processo educativo, tais como as crenças e valores daquele que está a aprender, todavia sabemos que eles influenciam em determinadas ocasiões este procedimento. O objetivo de todo o esforço de ensinar é que o outro mude seu comportamento em prática a tudo aquilo que lhe foi ensinado.

O didatismo, não leva em conta esses fatores externos, que por sua vez podem influenciar na prática do ensino-aprendizagem, pois de acordo com a FUNASA (2007, p. 7)

O didatismo ocorre na medida em que essas atividades tendem a ser desenvolvidas sem considerar as situações de risco de cada comunidade e sem levar em conta o conjunto das ações de saúde desencadeadas nesse sentido, ou seja, desenvolvem-se aparentemente como um fim em si mesmas.

Isso significa, portanto, que a eficácia da educação em saúde na qual esteja construída sob o didatismo estaria dependente apenas das tecnologias de ensino e aspectos relativos ao conteúdo sem haver o mínimo questionamento quanto aos resultados individuais e coletivos e, sem colocar em questão o vínculo co’os problemas de saúde e condições de vida de grupos sociais específicos.

Ao estabelecer Diretrizes de Educação em Saúde, a Funasa (FUNASA, 2007, p. 1921), almejando a promoção da saúde, define como básicos e importantes os seguintes pontos:

- $\quad$ A Educação em Saúde é uma prática social, cujo processo contribui para a formação da consciência crítica das pessoas a respeito de seus problemas de saúde, a partir da sua realidade, e estimula a busca de soluções e organização para a ação individual e coletiva;

- Reafirma a educação como um sistema baseado na participação das pessoas visando à mudança (transformação) de determinada situação, rompendo com o paradigma da concepção estática de educação como transferência de conhecimentos, habilidades e destrezas; [...]

- A prática de saúde, enquanto prática educativa, tem por base o processo de capacitação de indivíduos e grupos para atuarem sobre a realidade e transformá-la;

- A prática educativa parte do princípio de respeitar o universo cultural das pessoas e as formas de organização da comunidade, considera que todas as pessoas acumulam experiências, valores, crenças, conhecimentos e são detentoras de um potencial para se organizar e agir.

- A dimensão educativa é inerente aos processos de trabalho em saúde, seja ao nível da sua formalização nas práticas pedagógicas reconhecidas por sua delimitação ao espaço da escola ou dos serviços de assistência à saúde, mas também pela saúde e educação constituírem-se como práticas sociais que se articulam na vida de todo ser humano. 
Todos esses pressupostos definidos pela Funasa cita direta ou indiretamente que a educação em saúde deve ser construída observando as condições sociais dos usuários do sistema de saúde e também que deve ser construída junto deles.

Em conformidade com Alves (2005) existem dois modelos de práticas de educação em saúde que podem ser denominados como modelo tradicional e modelo dialógico. Alves também afirma que esses modelos são extremos reconhece que pode haver outros métodos intermediários.

O modelo chamado de tradicional tem como principal foco a intervenção curativa da moléstia alicerçada no referencial teórico biologicista, preconizando a prevenção da doença através de mudanças de comportamento e atitudes individuais, segundo Smeke \& Oliveira (2001) e Chiesa \& Veríssimo (2003), ou seja, a relação entre profissionais e usuários pode ser caracterizada como assimétrica, uma vez que os usuários são tomados como indivíduos carentes de informação em saúde. Neste modelo, semelhante ao didatismo o profissional é posto como o detentor do saber técnico-científico, enquanto o usuário é apenas aquele ser sem luz alguma de conhecimento. Desta maneira, o profissional se caracteriza como uma figura paterna, mostrando ao usuário o que fazer e como fazer a prática da saúde. Outro ponto que é viável enfatizar de acordo com Rice \& Candeias (1989) é que esse tipo de modelo tem efeito temporário em relação à mudança de hábitos e condutas, pois esses usuários reagem com o estímulo e, após a supressão desse estímulo, o comportamento vai tendendo a ex tinção.

Em objeção ao paradigma tradicionalista de prática de educação em saúde, temos o modelo dialógico, que segundo Ayres (2001) trabalha o âmbito, isto é, a perspectiva dos usuários das ações de saúde. Pensando dessa forma esse modelo apresenta segundo Briceño-Léon (1996) dois princípios básicos nas orientações das práticas de saúde, onde se faz necessário primeiramente conhecer e caracterizar os usuários que se destinam as ações em saúde, na qual incluem hábitos, crenças, situação social e seu papel diante da sociedade em geral. Já o segundo pricípio parte para a integração desses indivíduos, onde o diálogo é o seu instrumento essencial. No modelo dialógico o usuário é posto como sujeito detentor de um saber, que embora longe do saber técnico-científico não é inválido pelos serviços de saúde. E é nesse tipo de modelo, em conformidade com Briceño-Léon (1996) que profissionais e usuários se igualam, isto é, atuam como iguais, mesmo que tenham e atuem em papeis diferentes, pois o objetivo da educação dialógica é transformar saberes existente e não de informa-los, visando assim o crescimento da autonomia e da responsabilidade dos indivíduos frente aos cuidados co’a saúde, não sendo mais uma imposição técnico-científico detido pelo ser profissional da saúde. 


\section{CONSIDERAÇÕES FINAIS}

Mediante o que foi exposto, observa-se que a educação em saúde é caracterizada como um processo de ensino no qual usuários do serviço de saúde e profissionais deste serviço tende a buscar métodos para a propagação do conhecimento da saúde, entretanto, esses métodos podem não ser muito viáveis para a população, uma vez que deixam a desejar quanto ao seu tempo de duração, alcance de classes sociais e afins. Foi visto que foram abordados a priori dois métodos bastante distintos, o primeiro método denominado tradicional e o segundo dialógico. Para enfatizar aqui qual desses dois métodos seria o mais viável para ser utilizado nas práticas de educação em saúde, seja em unidades básicas de saúde, seja em hospitais ou até mesmo em escolas, devemos observar qual a necessidade desses indivíduos que terão contato com essa prática. Nesse âmbito, devemos ter a consciência de que existem grupos e grupos sociais de risco in locus, e que eles precisam ser orientados.

Visto que o modelo dialógico atende essas necessidades, uma vez que trata esses grupos como detentores de algum conhecimento que somente precisa ser aprimorado; ele trata também o indivíduo como um ser igual a qualquer outro e não permite que ocorram possibilidades de um eventual ditatorialismo, vamos assim dizer, por parte dos profissionais de saúde, uma vez que eles podem se achar os portadores de todo o conhecimento técnico-científico, não atendendo realmente as necessidades dos usuários. A principal estratégia desse modelo é a comunicação sob a forma de diálogos, onde visa à construção do saber acerca do processo saúde-doença-cuidado, possibilitando o indivíduo (usuário) a decidir qual o melhor caminho para desenvolver, manter e reaver sua saúde.

\section{REFERÊNCIAS}

1. ALVES, V. S. A health education model for the Family Health Program: towards comprehensive health care and model reorientation, Interface - Comunic., Saúde, Educ., v.9, n.16, p.39-52, set.2004/fev.2005.

2. AYRES, J. R. C. M. Sujeito, intersubjetividade e práticas de saúde. Ciênc. Saúde Colet., v.6, n.1, p.63-72, 2001.

3. BRASIL, Fundação Nacional de Saúde. Diretrizes de Educação em Saúde Visando à Promoção da Saúde: documento base - documento I. Brasília: Funasa, 2007. 70 p.: il. 
4. BRICEÑO-LÉON, R. Siete tesis sobre la educación sanitaria para la participación comunitaria. Cad. Saúde Pública, v.12, n.1, p.7-30, jan/mar., 1996.

5. CHIESA, A. M.; VERÍSSIMO, M. D. L. Ó. R. A educação em saúde na prática do PSF. Manual de enfermagem. Disponível em: <www.idssaude.org.br/enfermagem>. Acesso em: 12 out. 2015.

6. GAVIDIA, V. Salud, educación y calidad de vida: de cómo las concepciones del profesorado inciden en la salud. Santa Fe de Bogotá: Magistério; 1998.

7. RICE, M.; CANDEIAS, N. M. F. Padrões mínimos da prática da educação em saúde: um projeto pioneiro. Revista de Saúde Pública, v.23, n.4, p. 347-53, 1989.

8. SMEKE, E. L. M.; OLIVEIRA, N. L. S. Educação em saúde e concepções de sujeito. In: VASCONCELOS, E. M. (Org.) A saúde nas palavras e nos gestos: reflexões da rede educação popular e saúde. São Paulo: HUCITEC, 2001. p.11536.

9. VASCONCELOS, M. et al. Módulo 4: práticas pedagógicas em atenção básica a saúde. Tecnologias para abordagem ao indivíduo, família e comunidade. Belo Horizonte: Editora UFMG - Nescon UFMG, 2009. 70 p. 